\title{
Knockdown of LINC00657 inhibits the viability, migration and invasion of pancreatic cancer cells by regulating the miR-520h/CKS1B axis
}

\author{
PENG LI ${ }^{1}$, HONGSHENG WANG ${ }^{1}$, YING TANG ${ }^{2}$, SHUO SUN ${ }^{1}$, \\ YUE MA $^{1}$, YANSONG XU ${ }^{1}$ and GUANGYU CHEN ${ }^{1}$ \\ Departments of ${ }^{1}$ Hepatobiliary and Pancreatic Surgery and ${ }^{2}$ Nursing, Affiliated Hospital of \\ Beihua University, Jilin, Jilin 132011, P.R. China
}

Received September 18, 2020; Accepted May 13, 2021

DOI: $10.3892 /$ etm.2021.10576

\begin{abstract}
Long non-coding RNA LINC00657 has a critical role in multiple cancers. The aim of the present study was to investigate the regulatory effect of LINC00657 in pancreatic cancer (PC) and reveal its molecular mechanism of function. The expression levels of LINC00657 and microRNA (miR)-520h were detected by reverse transcription-quantitative PCR in PC tissues and cell lines. MTT, wound healing and Transwell assays were used to detect cell viability, migration and invasion, respectively. Dual-luciferase reporter assay was utilized to examine the relationship between LINC00657 and miR-520h and that between miR-520h and cyclin-dependent kinases regulatory subunit 1 (CKS1B). Western blotting was performed to detect CKS1B expression. The expression levels of LINC00657 and CKS1B were enhanced and miR-520h expression level was reduced in PC tissues and cell lines compared with adjacent normal tissues or HPDE6 cells. LINC00657 knockdown decreased the viability, migration and invasion of PC cells. Additionally, LINC00657 targeted miR-520h and negatively modulated miR-520h expression. Furthermore, miR-520h overexpression inhibited the viability, migration and invasion of PC cells. In addition, miR-520h targeted CKS1B and reversely regulated CKS1B expression. miR-520h inhibition and CKS1B overexpression alleviated the inhibition effect of LINC00657 knockdown on the viability, migration and invasion of PACA-2 PC cells. In conclusion, the results of the present study demonstrated that LINC00657 knockdown repressed the viability, migration and invasion of PC cells via targeting the miR-520h/CKS1B axis, which may offer a future target for PC therapy.
\end{abstract}

Correspondence to: Dr Guangyu Chen, Department of Hepatobiliary and Pancreatic Surgery, Affiliated Hospital of Beihua University, 12 Jiefang Zhong Road, Chuanying, Jilin, Jilin 132011, P.R. China

E-mail: chenguangyu214@163.com

Key words: pancreatic cancer, LINC00657, microRNA-520h, cyclin-dependent kinases regulatory subunit 1

\section{Introduction}

Pancreatic cancer (PC) is one of the deadliest cancers, ranking among the top five causes of cancer-associated mortality $(1,2)$. Genetics, smoking, diabetes and obesity have been associated with an increased risk of PC (3). In 2017, the new PC cases in China accounted for $18.66 \%$ of all new PC cases worldwide, and the incidence of PC is still rising $(4,5)$. Owing to the invasiveness of PC cells in the early stages, it is difficult to completely cure PC through surgery (6). Despite the progress made regarding existing treatments for PC, including surgery, immunotherapy and chemotherapy, the 5-year survival rate of patients is only $5 \%$ worldwide $(7,8)$. Therefore, it is critical to investigate the underlying mechanisms of $\mathrm{PC}$ and discover novel targets for PC therapy.

Long non-coding RNAs (lncRNAs) serve major roles in the complicated regulatory network of the tumour development process, including PC (9). For instance, decreased KCNK15-AS1 expression has been indicated to suppress cell migration and invasion in PC (10). BX111887 downregulation has been demonstrated to inhibits PC cell migration and invasion and tumour growth in vivo (11). Emerging evidence has revealed that the reduction of LINC00657 suppresses the development of human cancers, such as colon (12), oesophageal squamous cell (13) and pancreatic ductal (14) cancer. However, the function of LINC00657 and its underlying mechanism in $\mathrm{PC}$ development requires further elucidation.

MicroRNAs (miRNAs/miRs) are short non-coding RNAs that can alter gene expression in several biological processes (15). Previous studies have indicated that altered expression of miRNAs, such as miR-9-5p (16), miR-138-5p (17) and miR-142-5p (18), is associated with PC progression. miR-520h has been reported to be associated with PC growth. For instance, Wang et al (19) demonstrated that miR-520h upregulation inhibited the migration and invasion of PC cells. It has been reported that the regulatory function of miRNAs in PC development is generally regulated by lncRNAs. Gao et al (20) revealed that decreased expression of lncRNA ZEB2-AS1 inhibited PC cell growth and invasion by regulating miR-204. The effect of miR-133a overexpression on the inhibition of PC cell viability has been indicated to be regulated 
by lncRNA X-inactive specific transcript (21). Knockdown of LINC00657 has been demonstrated to inhibit the viability, migration and invasion of pancreatic ductal adenocarcinoma (PDAC) cells via targeting miR-433 (14). However, the interaction between miR-520h and LINC00657 in PC progression has not been revealed.

In the present study, the expression levels of LINC00657, miR-520h and cyclin-dependent kinases regulatory subunit 1 (CKS1B) were examined in PC tissues and cell lines. Moreover, the effects of LINC00657 knockdown on the viability, migration and invasion of PC cell lines were investigated. The association between LINC00657 and the miR-520h/CKS1B axis was further investigated in PC cell lines. The results of the current study may provide a potential novel target for PC therapy.

\section{Materials and methods}

Tissue samples. Sixty patients with PC (31 male and 29 female, mean age, $62 \pm 11$ years old) were recruited between January 2017 and October 2018 in the Affiliated Hospital of Beihua University (Jilin, China). All patients had not received local or systemic treatment before surgery and PC was staged (IA/IB/IIA and IIB/III/IV) in accordance with the 8th edition of the American Joint Committee on Cancer tumour-node-metastasis (TNM) classification (22). PC tissue samples and corresponding adjacent normal tissues $(5 \mathrm{~cm}$ away from tumors) from different TNM stages were acquired by surgical resection. Each specimen was diagnosed by histology. All patients provided informed consent, and the Ethics Committee of the Affiliated Hospital of Beihua University approved the present study (Jilin, China; approval no. 20-18).

Cell culture. The normal human pancreatic duct epithelial cell line (HPDE6) is a cell line of male origin that contains the E6/E7 gene of human papillomavirus type 16 and is positive for nestin [karyotype: 45 47, XY, der (21) t (17; 21) (q21.3; p13) and 46, XY, t $(3 ; 18)(\mathrm{p} 21.1 ; \mathrm{q} 11.2)$, der $(21) \mathrm{t}(17 ; 21)$ (q21.3; p13)]. HPDE6 and PC cell lines (SW1990, PACA-2 and BXPC-3) were purchased from American Tissue Culture Collection. SW1990 cells were cultured in Leibovitz's L-15 Medium (MilliporeSigma) containing 15\% FBS (Gibco; Thermo Fisher Scientific, Inc.). HPDE6 and PACA-2 cells were cultured in DMEM containing 10\% FBS (both from Gibco; Thermo Fisher Scientific, Inc.). BXPC-3 cells were cultured in RPMI-1640 medium containing 10\% FBS (both from Gibco; Thermo Fisher Scientific, Inc.). All cells were cultured at $37^{\circ} \mathrm{C}$ in an incubator (MCO-15AC; Sanyo Electric Co., Ltd.) with $5 \% \mathrm{CO}_{2}$.

Cell transfection. Short hairpin (sh)RNA negative control (NC) (sh-NC), sh-LINC00657-1 and sh-LINC00657-2 were purchased from GeneCopoeia Inc. miR mimics NC (miR-NC, 5'-UUCUCCGAACGUGUCACGUTT-3'), miR-520h mimics (5'-ACAAAGUGCUUCCCUUUAGAGU-3'), inhibitor NC (5'-UUCUCCGAACGUGUCACGUTT-3') and miR-520h inhibitor (5'-CCCUCUACAGGGAAGCGCUU-3'), as well as pcDNA-NC and pcDNA-CKS1B were obtained from Shanghai GenePharma Co., Ltd. The aforementioned mimics, inhibitors, plasmids and NC (all, $50 \mathrm{nM}$ ) were then transfected into PACA-2 and/or SW1990 cells (6×10 5 cells/well) using Lipofectamine $3000^{\circledR}$ (Invitrogen; Thermo Fisher Scientific, Inc.) at $37^{\circ} \mathrm{C}$. Two days after transfection, the cells were harvested to perform the following experiments.

Reverse transcription-quantitative PCR (RT-qPCR) assay. Total RNA was extracted from PC tissues and PC cell lines (SW1990, PACA-2, and BXPC-3) using TRIzol ${ }^{\circledR}$ reagent (Invitrogen; Thermo Fisher Scientific, Inc.). According to the manufacturer's instructions, cDNA was synthesized using the First-Strand cDNA Synthesis kit (APeXBIO Technology LLC) and RT-qPCR was performed with SYBR Green FAST Mastermix (Qiagen GmbH). The expression of LINC00657 and CKS1B was normalized to that of GAPDH. The expression of miR-520h was normalized to that of U6. The primer sequences used for RT-qPCR are listed in Table I. The PCR conditions were as follows: $95^{\circ} \mathrm{C}$ for $10 \mathrm{~min}$, followed by 40 cycles of $95^{\circ} \mathrm{C}$ for $15 \mathrm{sec}, 60^{\circ} \mathrm{C}$ for $1 \mathrm{~min}$ and $72^{\circ} \mathrm{C}$ for $1 \mathrm{~min}$. The $2^{-\Delta \Delta \mathrm{Cq}}$ method was used to evaluate relative gene expression (23).

Target prediction. The miRNA targets of LINC00657 were predicted using LncBase Predicted v.2 software (http://carolina.imis.athena-innovation.gr/diana_tools/web/index. php?r=lncbasev2/index-predicted) and StarBase software v.2 (http://starbase.sysu.edu.cn/). A total of 302 and 272 miRNA targets was predicted, respectively. Among these miRNA targets, miR-520h was selected because of its important role in PC (19) and unknown regulatory relationship with LINC00657. In addition, the mRNA targets of miR-520h were predicted using miRDB database (http://mirdb.org/), and 916 targets were predicted. As CKS1B has been associated with the pathogenesis of numerous human cancers such as retinoblastoma (24), CRC (25) and GC (26), CKS1B was selected for subsequent experiments.

Bioinformatics analysis. The Cancer Genome Atlas (TCGA; https://www.cancer.gov/about-nci/organization/ccg/research/structural-genomics/tcga) was used to examine the expression levels of LINC00657 and CKS1B in PC patients $(n=179)$ and normal controls $(n=171)$.

Dual-luciferase reporter (DLR) assay. The 3'-untranslated region of LINC00657 incorporating the predicted wild type (Wt) or mutant (Mut) binding sites of miR-520h were cloned into the pGL3 vector (Promega Corporation) to construct LINC00657 Wt and LINC00657 Mut plasmids. The CKS1B Wt and CKS1B Mut reporter plasmids were constructed in a similar way. Lipofectamine 3000 (Invitrogen; Thermo Fisher Scientific, Inc.) was used to co-transfect a Wt or Mut luciferase reporter and miR-520h mimics or miR-NC into SW1990 and PACA- 2 cells. Then, the DLR assay kit (Promega Corporation) was used for detecting the relative luciferase activity $48 \mathrm{~h}$ after transfection. The activity of firefly luciferase was normalized to that of Renilla luciferase.

MTT assay. After transfection, PACA-2 and/or SW1990 cells were plated in 96 -well plates $\left(1 \times 10^{3}\right.$ cells/well) and cultured for $0,24,48,72$ and $96 \mathrm{~h}$. Subsequently, $15 \mu \mathrm{l}$ MTT solution $(5 \mathrm{mg} / \mathrm{ml})$ was added to each well. After $4 \mathrm{~h}, 200 \mu \mathrm{l}$ 
Table I. Primers used for reverse transcription-quantitative PCR.

\begin{tabular}{lll}
\hline Gene & \multicolumn{1}{c}{ Forward $\left(5^{\prime}-3^{\prime}\right)$} & \multicolumn{1}{c}{ Reverse $\left(5^{\prime}-3^{\prime}\right)$} \\
\hline LINC00657 & TGATAGGATACATCTTGGACATGGA & AACCTAATGAACAAGTCCTGACATACA \\
miR-520h & TCGCGACAAAGTGCTTCCCT & GTGCAGGGTCCGAGGT \\
CKS1B & TATTCGGACAAATACGACGACG & CGCCAAGATTCCTCCATTCAGA \\
GAPDH & GCGAGATCGCACTCATCATCT & TCAGTGGTGGACCTGACC \\
U6 & CTCGCTTCGGCAGCACA & AACGCTTCACGAATTTGCGT
\end{tabular}

miR, microRNA; CKS1B, cyclin-dependent kinases regulatory subunit 1 .

DMSO was added. The optical density value was measured at $570 \mathrm{~nm}$ using a spectrophotometer (Thermo Fisher Scientific, Inc.).

Cell doubling time assay. After reaching $80 \%$ confluence, the transfected SW1990 and PACA-2 cells were trypsinized with $0.25 \%$ trypsin at $37^{\circ} \mathrm{C}$ for $10 \mathrm{~min}$ to create a single-cell suspension. The suspension was seeded in a six-well plate at $2 \times 10^{3}$ cells/well. The cells were cultured for 7 days and then digested and counted. Doubling time was calculated as $7 \mathrm{x}[\lg 2 /(\operatorname{lgN} 0-\operatorname{lgN} 7)] \mathrm{x} 24(\mathrm{~N} 0$, cell number at day $0 ; \mathrm{N} 7$, cell number at day 7$)$.

Wound healing assay. PACA-2 and/or SW1990 cells were seeded into a six-well plate and cultured in medium (Leibovitz's L-15 Medium for SW1990 and DMEM for PACA-2) supplemented with $10 \%$ FBS until the cells were grown to $100 \%$ confluence. A $10 \mu 1$ pipette tip was used to create a scratch wound in the cell monolayer. The medium was aspirated to remove the detached cells, and serum-free DMEM and/or Leibovitz's L-15 Medium were added to the 6 -well plate. At 0 and $24 \mathrm{~h}$, cell migration was observed using an Olympus inverted light microscope (magnification, $\mathrm{x} 400$; Olympus Corporation) and photographed using a Cyber-shot camera (Sony Corporation). Image-Pro Plus 6.0 software (Media Cybernetics, Inc.) was used to measure the wound distance at 0 and $24 \mathrm{~h}$. The wound heading rate was calculated as follows: $(0 \mathrm{~h}$ width $-24 \mathrm{~h}$ width $) / 0 \mathrm{~h}$ width $\mathrm{x} 100 \%$.

Transwell assay. Transwell inserts (8.0 $\mu \mathrm{m}, \mathrm{BD}$ Biosciences) were placed on 24-well plates to create top and bottom chambers. The transfected PACA-2 and/or SW1990 cells in serum-free DMEM and/or Leibovitz's L-15 Medium were cultured in the top compartment precoated at $37^{\circ} \mathrm{C}$ for $30 \mathrm{~min}$ with Matrigel (BD Biosciences). The bottom compartment was filled with DMEM and/or Leibovitz's L-15 Medium containing $20 \%$ FBS. After $24 \mathrm{~h}$, the cells on the lower compartment were fixed in $75 \%$ methanol at $4^{\circ} \mathrm{C}$ for $10 \mathrm{~min}$ and stained with $0.3 \%$ crystal violet at $37^{\circ} \mathrm{C}$ for $30 \mathrm{~min}$. Finally, an inverted optical microscope (magnification, $\mathrm{x} 400$; Olympus Corporation) was used to capture the photos of migrated cells.

Western blot analysis. RIPA lysis solution (Beyotime Institute of Biotechnology) was used to obtain total protein from SW1990 and PACA-2 cells. The protein concentration was detected by the BCA Protein Assay kit (Abcam). Protein samples $(20 \mu \mathrm{g} /$ lane $)$ were separated via $10 \%$ SDS-PAGE and then transferred onto PVDF membranes (MilliporeSigma). The membranes were blocked with $5 \%$ skimmed milk at $25^{\circ} \mathrm{C}$ for $1 \mathrm{~h}$ and incubated overnight at $4^{\circ} \mathrm{C}$ with anti-CKS1B $(1: 1,000$; cat. no. ab72639; Abcam) and anti- $\beta$-tubulin (1:1,000; cat. no. ab7291; Abcam) antibodies. Subsequently, the membranes were incubated with an horse-radish peroxidase (HRP)-conjugated goat anti-rabbit secondary antibody (1:5,000, cat. no. ab205718; Abcam) at $37^{\circ} \mathrm{C}$ for $2 \mathrm{~h}$. The signals were detected using ECL reagent (Thermo Fisher Scientific, Inc.), and the immunoblots were analysed using Image $\mathrm{Lab}^{\mathrm{TM}}$ Software v.1.46 (Bio-Rad Laboratories, Inc.).

Statistical analysis. All experiments were conducted in triplicate in at least 3 independent experiments. Data analysis was performed using GraphPad Prism version 6 (GraphPad Software, Inc.), and the data are presented as the mean \pm standard deviation. The differences between two groups or among multiple groups were analysed by Student's t-test (paired, Figs. 1B, 3D and 5D; unpaired, Figs. 1C, 2C-E and 4C-E) or one-way ANOVA followed by Tukey's post-hoc test, respectively. Pearson's correlation analysis was carried out to assess correlations between the expression levels of different molecules. The differences of clinicopathological characteristics between patients with PC with low and high expression of LINC00657 was analysed via $\chi^{2}$ test. $\mathrm{P}<0.05$ was considered to indicate a statistically significant difference.

\section{Results}

LINC00657 expression is increased in PC tissues and cell lines. Firstly, The Cancer Genome Atlas (TCGA) was used to examine LINC00657 expression in PC, and it was revealed that LINC00657 expression was markedly upregulated in pancreatic adenocarcinoma (PAAD) compared with normal tissues (P<0.05; Fig. 1A). RT-qPCR data indicated that LINC00657 expression in $\mathrm{PC}$ tissues was enhanced compared with that in adjacent normal tissues $(\mathrm{P}<0.001$; Fig. 1B). LINC00657 expression in TNM stage IIB/III/IV was higher than that of stage IA/IB/IIA ( $\mathrm{P}<0.001$; Fig. 1C). In addition, LINC00657 expression was examined in PC cell lines and HPDE6 cells. The results indicated that LINC00657 expression was notably increased in PC cell lines, especially in SW1990 and PACA-2 cells, compared with HPDE6 cells (all P<0.01; Fig. 1D). Thus, these two cell lines were selected for subsequent experiments. As presented in Table II, there were significant differences 

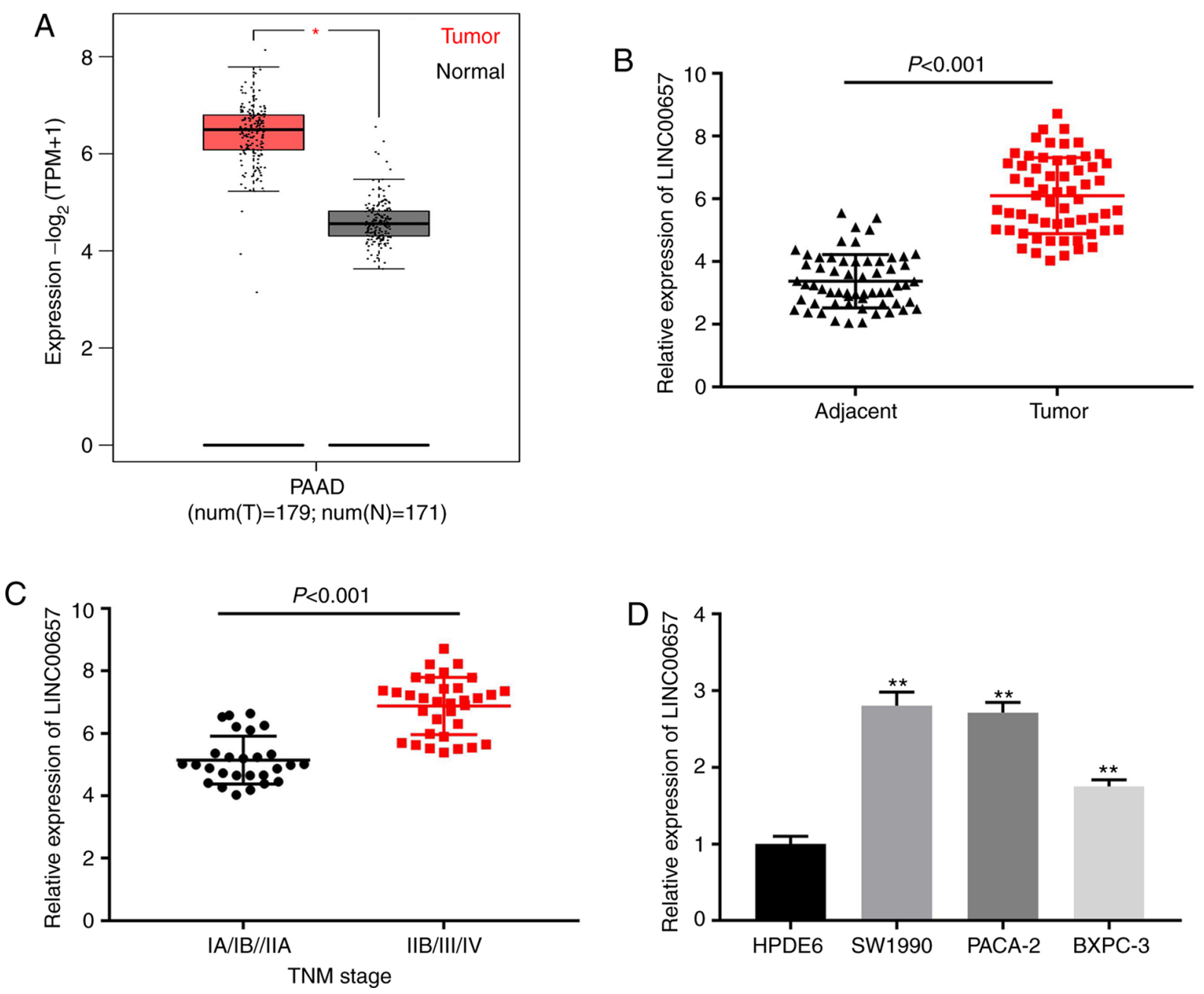

Figure 1. LINC00657 expression is increased in PC tissues and cell lines. (A) The expression of LINC00657 was evaluated using The Cancer Genome Atlas in PAAD tumours. "P<0.05 vs. normal tissues. (B) LINC00657 expression was detected via RT-qPCR in PC tissues and adjacent normal tissues. P<0.001 vs. adjacent normal tissues. (C) LINC00657 expression was detected via RT-qPCR in PC tissues with different TNM stages (IA/IB/IIA and IIB/III/IV). P<0.001 vs. stage IA/IIB/IIA. (D) LINC00657 expression was detected via RT-qPCR in PC cell lines (SW1990, PACA-2 and BXPC-3) and a pancreatic duct epithelial cell line (HPDE6). ${ }^{* *} \mathrm{P}<0.01$ vs. HPDE6. PAAD, pancreatic adenocarcinoma; RT-qPCR, reverse transcription-quantitative PCR; PC, pancreatic cancer; TNM, tumour-node-metastasis; num, number; T, tumour; N, normal.

among patients with $\mathrm{PC}$ with high and low expression of LINC00657 in the diameter $(\mathrm{P}=0.017)$, metastasis $(\mathrm{P}=0.002)$ and TNM stage parameters $(\mathrm{P}=0.010)$. These data suggested that LINC00657 may be a lncRNA with on oncogenic role in PC development.

Knockdown of LINC00657 inhibits the viability, migration and invasion of PC cells. To explore the function of LINC00657 in PC, sh-LINC00657-1 or sh-LINC00657-2 was initially transfected into SW1990 and PACA-2 cells. LINC00657 expression was significantly reduced both in the sh-LINC00657-1 and sh-LINC00657-2 group compared with the sh-NC group (both $\mathrm{P}<0.01$; Fig. 2A). sh-LINC00657-1 was utilized in subsequent experiments because of its greater silencing efficiency. MTT assay demonstrated that the cell viability of the sh-LINC00657-1 group was markedly inhibited compared with that of the sh-NC group in SW1990 and PACA-2 cells (both $\mathrm{P}<0.01$; Fig. 2B). As illustrated in Fig. 2C, a longer cell doubling time was determined in the sh-LINC00657-1 group than that in the sh-NC group $(\mathrm{P}<0.01)$. Moreover, LINC00657 knockdown inhibited the migration and invasion of SW1990 and PACA-2 cells (all $\mathrm{P}<0.01$; Fig. 2D and E). The aforementioned results indicated that knockdown of LINC00657 could inhibit the viability, migration and invasion of PC cells.

miR-520h is a target of LINC00657. To reveal the mechanism of LINC00657 function in PC, LncBase Predicted v.2 and StarBase software v.2 softwares were used to predict its target genes. A binding site between LINC00657 and miR-520h was observed (Fig. 3A). Silencing of LINC00657 increased the expression level of miR-520h in SW1990 and PACA-2 cells (both $\mathrm{P}<0.01$; Fig. $3 \mathrm{~B}$ ). In addition, the DLR assay demonstrated that miR-520h mimics reduced the luciferase activity of LINC00657 Wt in SW1990 and PACA-2 cells (both $\mathrm{P}<0.01$; Fig. $3 \mathrm{C}$ ), further validating the association between LINC00657 and miR-520h. miR-520h expression in $\mathrm{PC}$ tissues lower than that in adjacent normal tissues $(\mathrm{P}<0.001$; Fig. 3D). As illustrated in Fig. 3E, there was a negative correlation between the expression levels of LINC00657 and miR-520h in PC tissues ( $r=-0.3412$; $\mathrm{P}=0.0076)$. Furthermore, miR-520h expression was also studied at the cellular level. miR-520h expression in PC cell 
Table II. Differences of clinicopathological characteristics between patients with pancreatic cancer with low and high expression of LINC00657.

\begin{tabular}{|c|c|c|c|c|}
\hline \multirow[b]{2}{*}{ Characteristics } & \multirow[b]{2}{*}{ Total number } & \multicolumn{2}{|c|}{$\begin{array}{c}\text { LINC00657 } \\
\text { expression }\end{array}$} & \multirow[b]{2}{*}{ P-value } \\
\hline & & Low & High & \\
\hline Sex & & & & 0.796 \\
\hline Male & 31 & 16 & 15 & \\
\hline Female & 29 & 14 & 15 & \\
\hline Age, years & & & & 0.602 \\
\hline$<60$ & 26 & 12 & 14 & \\
\hline$\geq 60$ & 34 & 18 & 16 & \\
\hline Differentiation & & & & 0.284 \\
\hline Well/moderate & 22 & 9 & 13 & \\
\hline Poor & 38 & 21 & 17 & \\
\hline Diameter, cm & & & & $0.017^{\mathrm{a}}$ \\
\hline$<2$ & 23 & 16 & 7 & \\
\hline$\geq 2$ & 37 & 14 & 23 & \\
\hline Metastasis & & & & $0.002^{\mathrm{a}}$ \\
\hline No & 24 & 18 & 6 & \\
\hline Yes & 36 & 12 & 24 & \\
\hline TNM stage & & & & $0.010^{\mathrm{a}}$ \\
\hline IA/IB+IIA & 27 & 21 & 6 & \\
\hline IIB+III+IV & 33 & 9 & 24 & \\
\hline
\end{tabular}

${ }^{\mathrm{a}} \mathrm{P}<0.05$. TNM, tumour-node-metastasis.

lines was decreased compared with that in HPDE6 cells (all $\mathrm{P}<0.01$; Fig. 3F). These results indicated that miR-520h may be a target of and negatively modulated by LINC00657, as well as a suppressor of PC.

miR-520h overexpression inhibits the viability, migration and invasion of PC cells. To further explore the potential role of miR-520h in PC, miR-520h mimics or inhibitor was primarily transfected into SW1990 and PACA-2 cells to determine the transfection efficiency. The results indicated that the expression of miR-520h was markedly increased after transfection with miR-520h mimics, and was decreased after transfection with miR-520h inhibitor in SW1990 and PACA-2 cells compared with their respective controls (all $\mathrm{P}<0.01$; Fig. 4A), suggesting that miR-520h mimics and miR-520h inhibitor was successfully transfected. miR-520h overexpression reduced the viability of SW1990 and PACA-2 cells (both $\mathrm{P}<0.01$; Fig. 4B). The results of the cell doubling time experiment demonstrated that the miR-520h mimics group exhibited a longer doubling time compared with that of the miR-NC group (both $\mathrm{P}<0.01$; Fig. 4C). Furthermore, miR-520h overexpression notably suppressed migration and invasion in SW1990 and PACA-2 cells (all $\mathrm{P}<0.01$; Fig. 4D and E). These results indicated that miR-520h overexpression could suppress the viability, invasion and migration of PC cells.
CKS1B is a target of miR-520h. The target genes of miR-520h were predicted using miRDB database, and CKS1B was indicated to have binding sites for miR-520h (Fig. 5A). The DLR assay revealed that miR-520h mimics notably inhibited the luciferase activity of CKS1B Wt in SW1990 and PACA-2 cells (both $\mathrm{P}<0.01$; Fig. $5 \mathrm{~B}$ ). TCGA analysis indicated that CKS1B expression was enhanced in PAAD compared with normal tissues $(\mathrm{P}<0.05$; Fig. 5C). Similarly, CKS1B expression in $\mathrm{PC}$ tissues was higher than that in adjacent normal tissues $(\mathrm{P}<0.001$; Fig. 5D). CKS1B expression was positively associated with that of LINC00657 ( $\mathrm{r}=0.3655 ; \mathrm{P}=0.0041 ;$ Fig. $5 \mathrm{E})$ and negatively associated with miR-520h expression in PC tissues ( $\mathrm{r}=-0.3931$; $\mathrm{P}=0.0019$; Fig. 5F). Subsequently, CKS1B expression was examined in vitro. The results revealed that CKS1B expression in PC cell lines was notably increased compared with that in HPDE6 cells (all $\mathrm{P}<0.01$; Fig. 5G). Overexpression of miR-520h significantly decreased CKS1B expression in SW1990 and PACA-2 cells (both $\mathrm{P}<0.01$; Fig. 5H). These findings indicated that miR-520h directly targeted CKS1B and inversely modulated CKS1B expression, as well as it may be an oncogene in PC.

LINC00657 knockdown inhibits PC tumorigenesis by regulating $\mathrm{miR}-520 \mathrm{~h}$ and $C K S 1 B$ expression. Finally, the effect of the LINC00657/miR-520h/CKS1B axis on PC progression was explored. As presented in Fig. 6A, western blotting demonstrated that the CKS1B protein level was significantly elevated in PACA-2 cells transfected with pcDNA-CKS1B compared with pcDNA-NC $(\mathrm{P}<0.01)$, which indicated that pcDNA-CKS1B was successfully transfected. LINC00657 knockdown inhibited the viability of PACA-2 cells, while this inhibitory effect was partially reversed by miR-520h inhibition and CKS1B overexpression (both $\mathrm{P}<0.01$; Fig. 6B). Moreover, miR-520h inhibition and CKS1B overexpression alleviated LINC00657 knockdown-induced inhibition of migration and invasion in PACA-2 cells (all $\mathrm{P}<0.01$; Fig. $6 \mathrm{C}$ and $\mathrm{D}$ ). The aforementioned data indicated that knockdown of LINC00657 inhibited the development of PC by regulating miR-520h and CKS1B expression.

\section{Discussion}

$\mathrm{PC}$ is a fatal malignant tumour that is mainly observed in males and exhibits an aggressive course (27). The existing literature has indicated that abnormally expressed lncRNAs serve a major role in the formation and growth of PC (28). In the present study, LINC00657 expression was indicated to be increased in PC tissues and cell lines compared with healthy tissues and control cells, respectively. Silencing of LINC00657 suppressed the viability, migration and invasion of PC cells. In addition, LINC00657 directly targeted miR-520h, and miR-520h directly targeted CKS1B. Further studies revealed that knockdown of LINC00657 inhibited PC tumorigenesis via targeting the miR-520h/CKS1B axis.

Previous studies have revealed that LINC00657 functioned as a cancer-promoting molecule in certain cancers, and its expression was enhanced in non-small cell lung cancer (NSCLC) (29), colorectal cancer (CRC) (30) and breast cancer (31). Bi et al (14) demonstrated that LINC00657 expression was increased in PDAC tissues and cell lines. Similarly, 

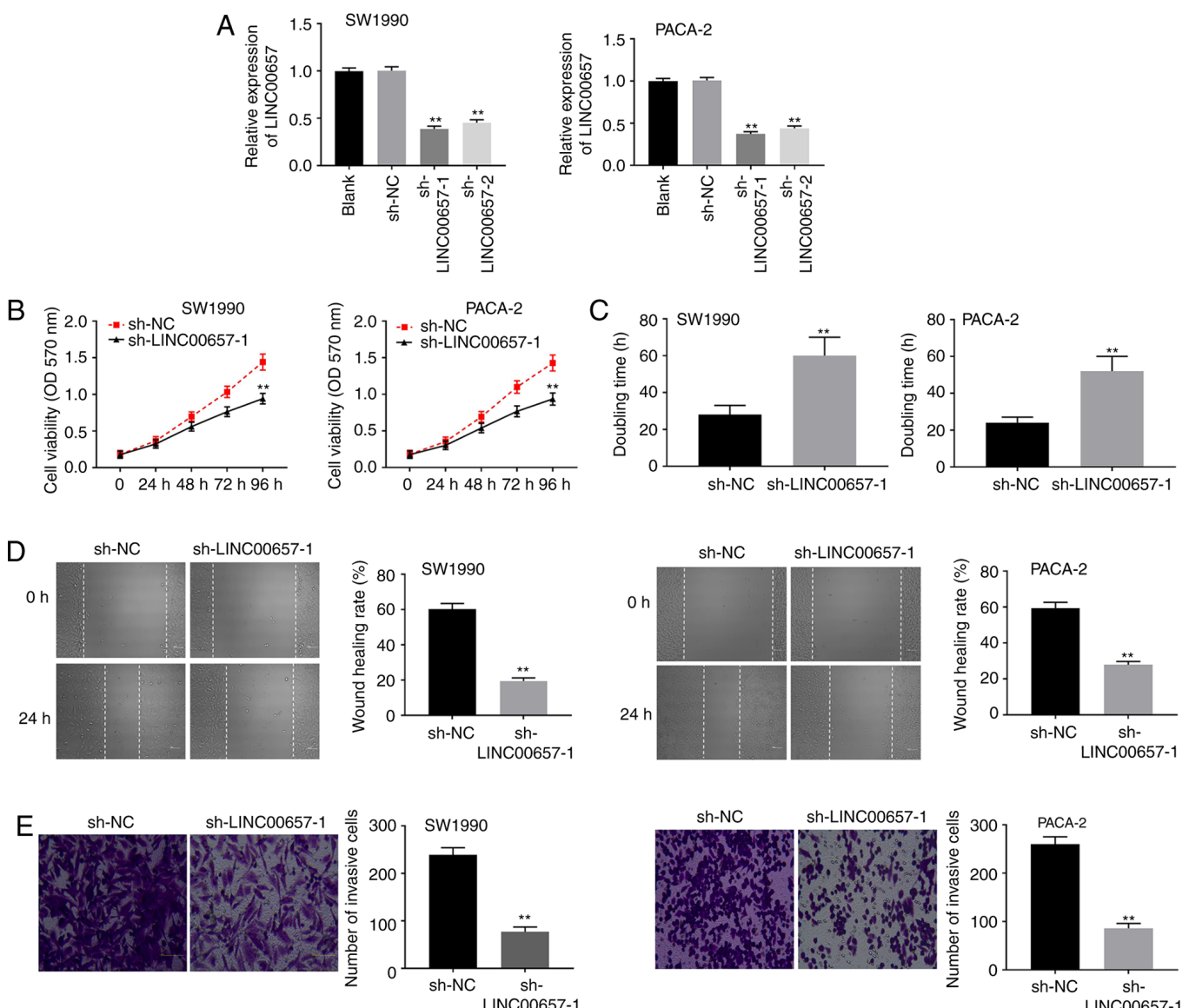

Figure 2. Knockdown of LINC00657 inhibits the viability, migration and invasion of pancreatic cancer cells. (A) LINC00657 expression was detected via reverse transcription-quantitative PCR in SW1990 and PACA-2 cells transfected with sh-NC, sh-LINC00657-1 or sh-LINC00657-2. ${ }^{* *} \mathrm{P}<0.01$ vs. sh-NC. (B) Cell viability was detected via MTT assay in SW1990 and PACA-2 cells transfected with sh-LINC00657-1 or sh-NC. ${ }^{* *} \mathrm{P}<0.01$ vs. sh-NC. (C) Doubling time of SW1990 and PACA-2 cells transfected with sh-LINC00657-1 or sh-NC. ${ }^{* *} \mathrm{P}<0.01$ vs. sh-NC. (D) Cell migration was analysed via wound healing assay and (E) cell invasion was examined via Transwell assay in SW1990 and PACA-2 cells transfected with sh-LINC00657-1 or sh-NC. Magnification, $x 400$. ${ }^{* *} \mathrm{P}<0.01$ vs. sh-NC. in SW1990 and PACA-2 cells transfected with sh-LINC00657-1 or sh-NC. ${ }^{* *} \mathrm{P}<0.01$ vs. sh-NC. NC, negative control; sh, short hairpin; OD, optical density.

$$
\begin{aligned}
& \text { A LINC00657 Wt } \quad 5^{\prime} \text {...AAACUGCUUGUGaUUGUGAAUGACUUUGU.... } 3^{\prime} \\
& \text { hsa-miR-520h } 3 \text {. } 1 \text {... I } 1 \text { I I I I I I I I I I I I I } \\
& \text { LINC00657 Mut } \quad 5^{\prime} \text {...AAACUGCUUGUGaUUGUGAAUGUGAAACA... 3' }
\end{aligned}
$$
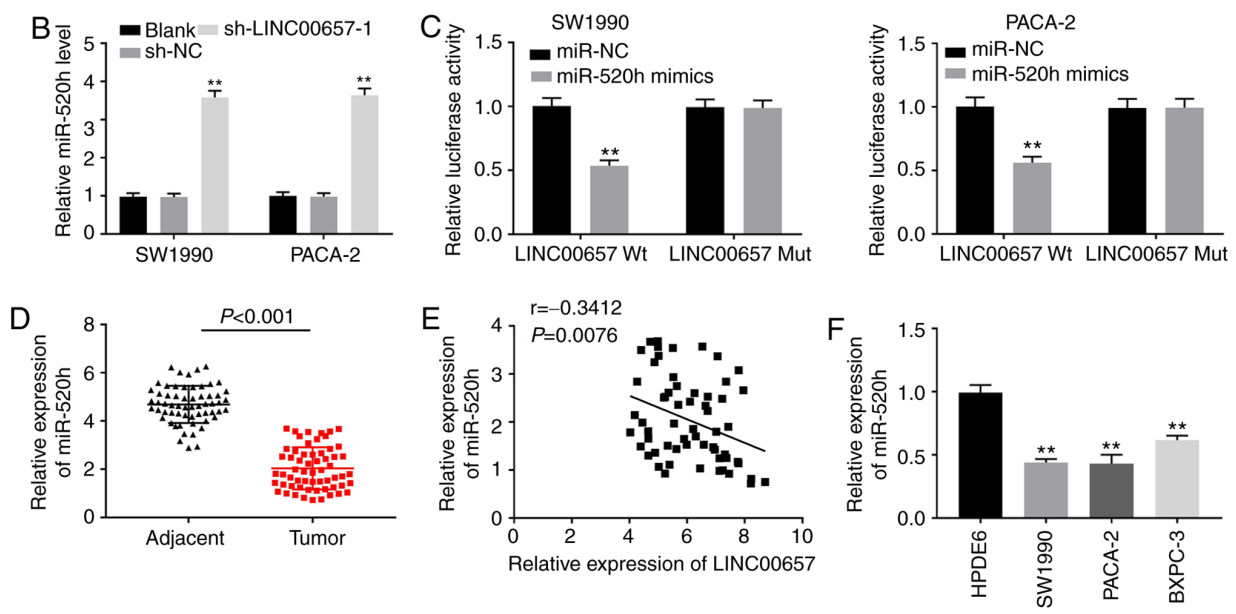

Figure 3. miR-520h is a target of LINC00657. (A) The potential binding sites between LINC00657 and miR-520h were predicted by LncBase Predicted v.2. (B) The expression of miR-520h was detected by RT-qPCR in SW1990 and PACA-2 cells transfected with sh-LINC00657-1 or sh-NC. ${ }^{* *} \mathrm{P}<0.01$ vs. sh-NC. (C) Dual-luciferase reporter assay confirmed the association between LINC00657 and miR-520h in SW1990 and PACA-2 cells. ${ }^{* * *} \mathrm{P}<0.01 \mathrm{vs.}$ miR-NC. (D) miR-520h expression was detected by RT-qPCR in PC tissues and adjacent normal tissues. P $<0.001$ vs. adjacent normal tissues. (E) The correlation between LINC00657 and miR-520h was evaluated by Pearson's correlation analysis. $r=-0.3412, P=0.0076$. (F) The expression of miR-520h was detected by RT-qPCR in PC cell lines and HPDE6 cells. ${ }^{* *} \mathrm{P}<0.01$ vs. HPDE6. PC, pancreatic cancer; NC, negative control; sh, short hairpin; miR, microRNA; RT-qPCR, reverse transcription-quantitative PCR; Wt, wild-type; Mut, mutant. 

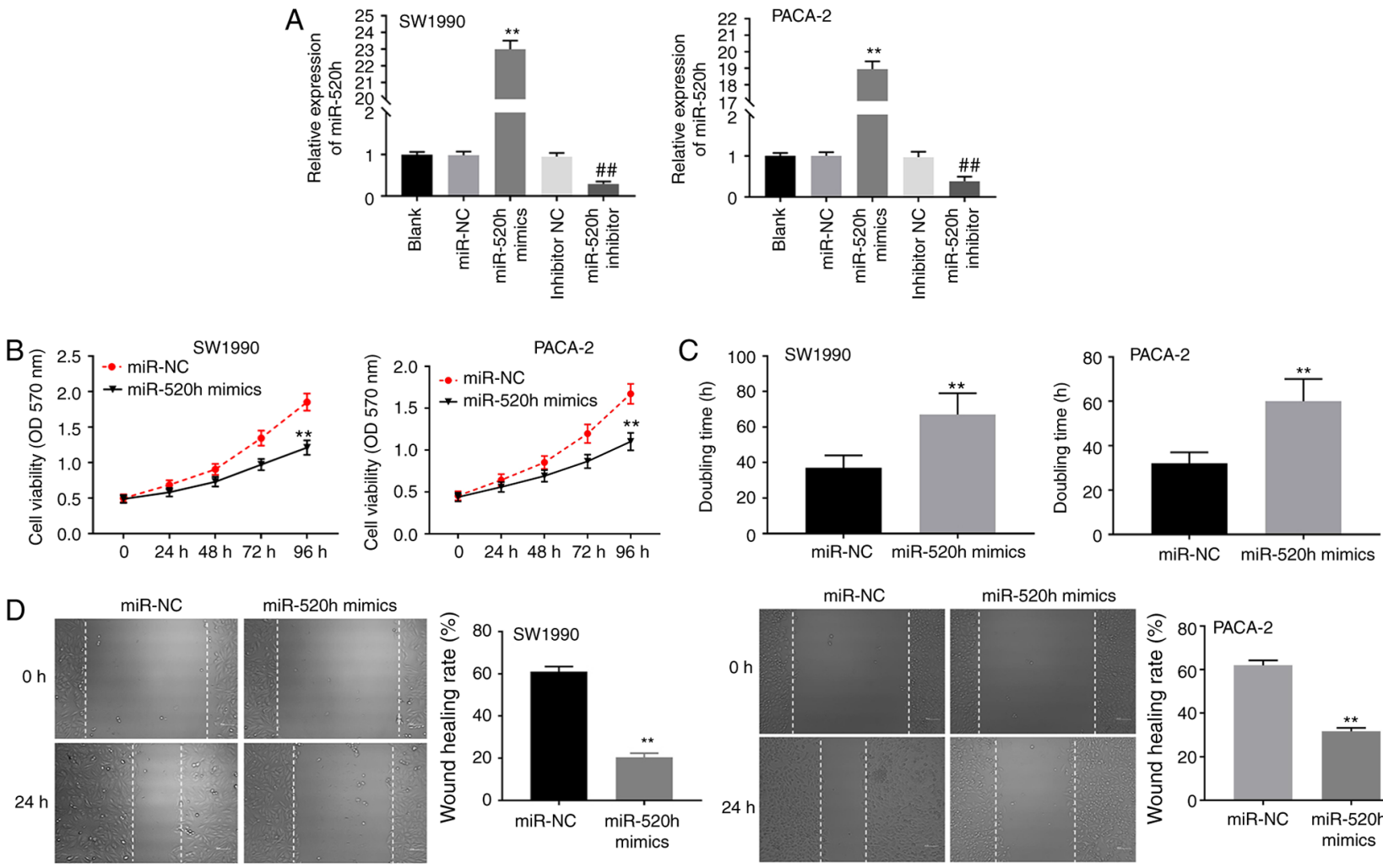

miR-520h mimics
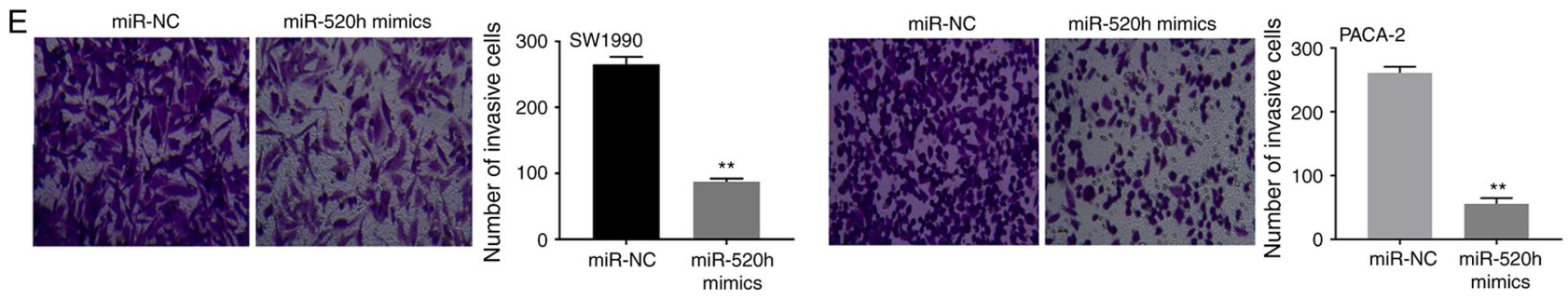

Figure 4. miR-520h overexpression inhibits the viability, migration and invasion of pancreatic cancer cells. (A) The expression of miR-520h was detected via reverse transcription-quantitative PCR in SW1990 and PACA-2 cells transfected with miR-520h mimics, miR-NC, miR-520h inhibitor or inhibitor NC. ${ }^{* *} \mathrm{P}<0.01$ vs. miR-NC; ${ }^{\# \#} \mathrm{P}<0.01$ vs. inhibitor NC. (B) Cell viability was detected via MTT assay in SW1990 and PACA-2 cells transfected with miR-520h mimics or miR-NC. ${ }^{* *} \mathrm{P}<0.01$ vs. miR-NC. (C) Doubling time of SW1990 and PACA-2 cells transfected with miR-520h mimics or miR-NC. ${ }^{* *} \mathrm{P}<0.01 \mathrm{vs}$. miR-NC. (D) Cell migration was examined via wound healing assay and (E) cell invasion was detected via Transwell assay in SW1990 and PACA-2 cells transfected with miR-520h mimics or miR-NC. Magnification, $\mathrm{x} 400 .{ }^{* * *} \mathrm{P}<0.01 \mathrm{vs}$. miR-NC. in SW1990 and PACA-2 cells transfected with miR-520h mimics or miR-NC. ${ }^{* *} \mathrm{P}<0.01$ vs. miR-NC. NC, negative control; miR, microRNA; OD, optical density.

the present study revealed LINC00657 was highly expressed in PC tissues and cell lines. The increase of LINC00657 was notably associated with tumour diameter, metastasis and TNM stage among the patients with PC. The aforementioned results indicated that LINC00657 was involved in PC development. Previous studies have reported that LINC00657 could regulate cellular processes in certain cancers. For instance, silencing LINC00657 has been indicated to inhibit the viability and migration of NSCLC cells (29). In oesophageal cancer, LINC00657 knockdown has been revealed to limit cell viability, migration and invasion (32). In the current study, LINC00657 knockdown inhibited the viability, migration and invasion of SW1990 and PACA-2 cells. The results of the present study suggested that silencing LINC00657 could inhibit PC development.

Numerous studies have indicated that LINC00657 regulates cancer development by interacting with miRNAs. For example, LINC00657 can competitively bind to miR-165-3p in oesophageal squamous cell carcinoma (13) and to miR-190a-3p in glioblastoma (33). In the present study, it was demonstrated that LINC00657 could target miR-520h. Additionally, LINC00657 knockdown increased miR-520h expression in PC cells, suggesting that LINC00657 was negatively associated with miR-520h. It has been indicated that miR-520h serves a pivotal role in the development of several cancers, and its expression has been demonstrated to be reduced in multiple myeloma cells (34) and breast cancer cells (35). In the current study, miR-520h was also weakly expressed in PC tissues and cell lines, suggesting that miR-520h may be a tumour suppressor gene in PC development. The tumour-suppressive function of miR-520h has been recognized in certain cancers. For example, overexpression of miR-520h inhibited cell migration and invasion in PC (19). Furthermore, miR-520h overexpression decreased the viability, migration and invasion of CRC cells (36). Similar to previous studies, in the present study miR-520h overexpression also suppressed the viability, 
A Position 96-103 of CKS1B Wt

hsa-miR-520h

CKS1B Mut

\section{$5^{\prime} \quad \ldots$ UGCCUUCUUGUUUCUCACUUUGA...3' | |||||| \\ $3^{\prime} \quad$ UGAGAUUUCCCUUCGUGAAACA $5^{\prime}$ \\ 5' UGCCUUCUUGUUUCUGUGAAACA $3^{\prime}$}

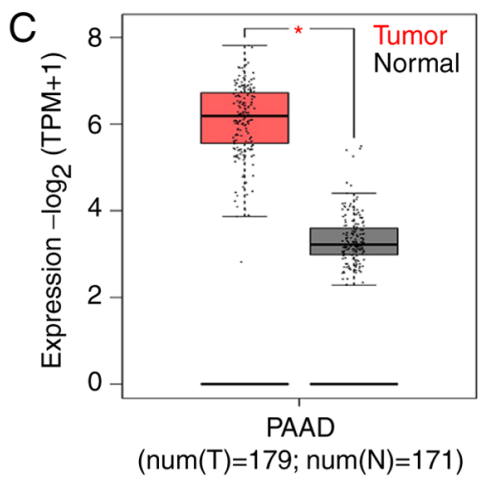

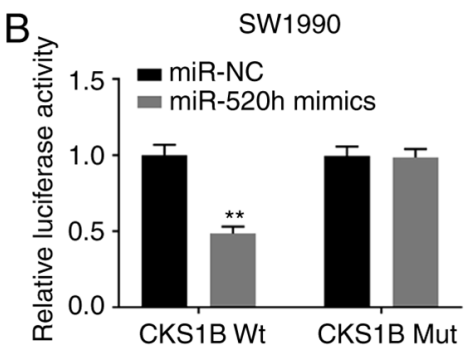

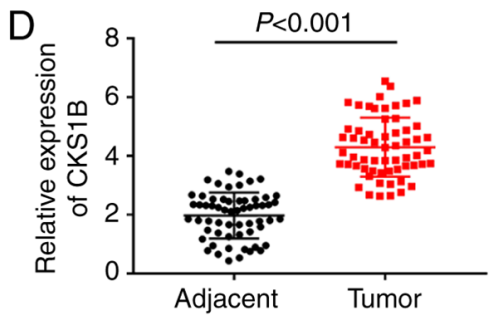

G

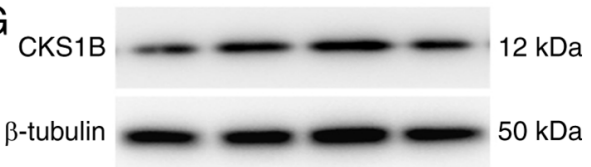

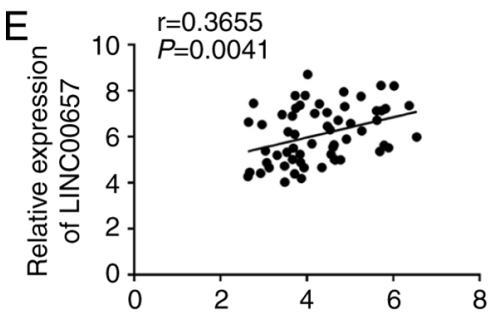

Relative expression of CKS1B

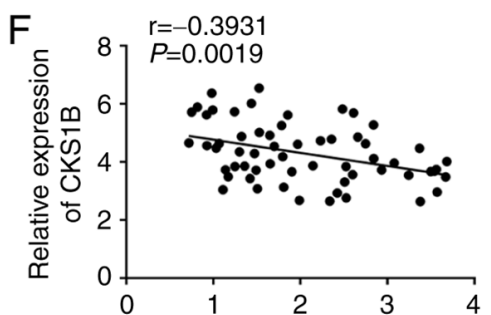

Relative expression of miR-520h
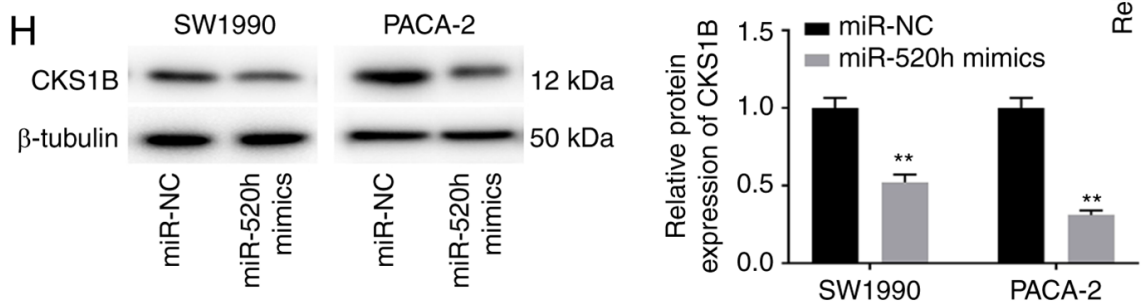

Figure 5. CKS1B is a target of miR-520h. (A) The putative binding sites of miR-520h and CKS1B were predicted using TargetScan. (B) Dual-luciferase reporter assay confirmed the association between miR-520h and CKS1B in SW1990 and PACA-2 cells. ${ }^{* * *} \mathrm{P}<0.01$ vs. miR-NC. (C) The expression of CKS1B was evaluated using The Cancer Genome Atlas in PAAD tumours. ${ }^{*} \mathrm{P}<0.05$ vs. normal tissues. (D) CKS1B expression was detected via reverse transcription-quantitative PCR in PC tissues and adjacent normal tissues. P $<0.001$. (E) The correlation between CKS1B and LINC00657 was evaluated using Pearson's correlation analysis. $\mathrm{r}=0.3655, \mathrm{P}=0.0041$. ( $\mathrm{F}$ ) The correlation between $\mathrm{CKS1B}$ and miR-520h was evaluated using Pearson's correlation analysis. $\mathrm{r}=-0.3931, \mathrm{P}=0.0019$. (G) The expression of CKS1B protein was detected via western blotting in PC cell lines and HPDE6 cells. ${ }^{* *} \mathrm{P}<0.01$ vs. HPDE6. (H) The expression of CKS1B protein was detected via western blotting in SW1990 and PACA-2 cells transfected with miR-520h mimics or miR-NC. ${ }^{* *} \mathrm{P}<0.01 \mathrm{vs}$. miR-NC. NC, negative control; miR, microRNA; CKS1B, cyclin-dependent kinases regulatory subunit 1; PAAD, pancreatic adenocarcinoma; PC, pancreatic cancer; TNM, tumour-node-metastasis; num, number; T, tumour; N, normal; Wt, wild-type; Mut, mutant.

invasion and migration of SW1990 and PACA-2 cells. The aforementioned results suggested that miR-520h overexpression could inhibit PC growth. As LINC00657 inversely regulated miR-520h, we hypothesized that LINC00657 knockdown may inhibit PC development by targeting miR-520h.

CKS1B is a member of the CKS protein family and is related to cell proliferation (37). CKS1B has been demonstrated to participate cancer growth and perform its function by acting as a target for miR-204 in GC (38) and miR-197 in NSCLC (39). In the current study, CKS1B was revealed to be a target of miR-520h and was reversely modulated by miR-520h in PC. Upregulation of CKS1B has been widely observed in multiple cancers, such as retinoblastoma (24), CRC (25) and GC (26). The present study demonstrated that CKS1B expression was also enhanced in PC tissues and cell lines compared with healthy tissues and control cells, respectively, suggesting that CKS1B may be an oncogenic molecule in PC development. In addition, Fujita et al (39) reported that the inhibitory effect of CKS1B knockdown on the viability, migration and invasion of NSCLC cells can be regulated by miR-197. miR-1258 overexpression has been indicated to suppress cell growth by targeting CKS1B in hepatocellular carcinoma cells (40). Thus, we hypothesized that miR-520h overexpression may inhibit the viability, migration and invasion of PC cells by targeting 
A

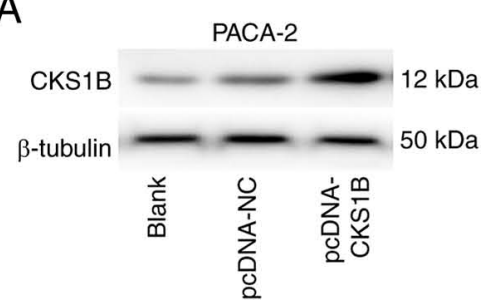

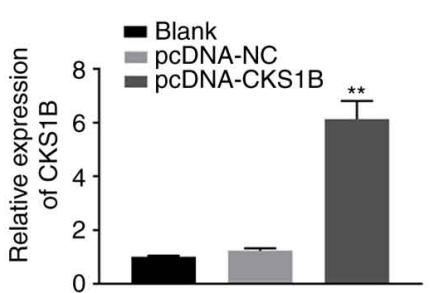
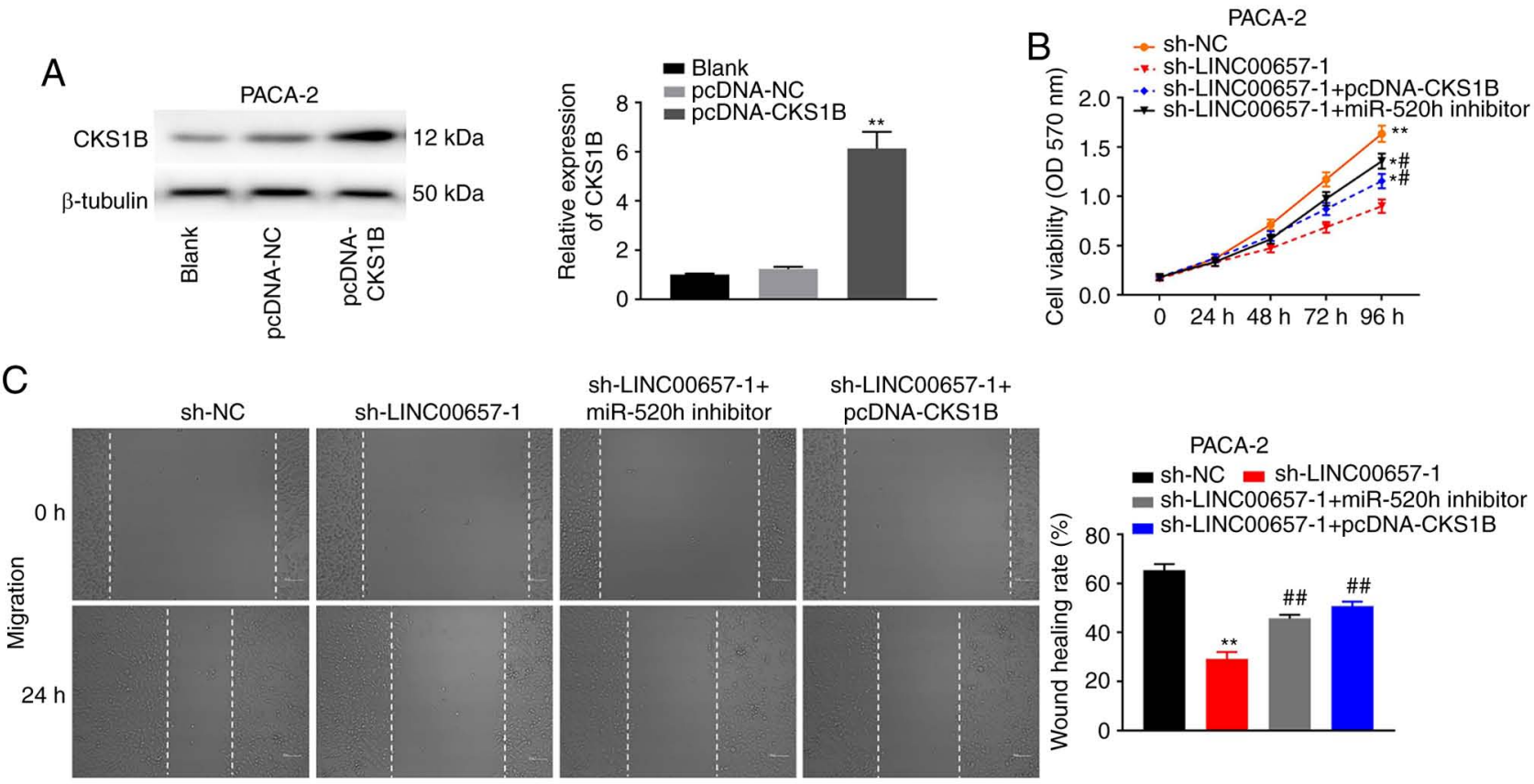

D

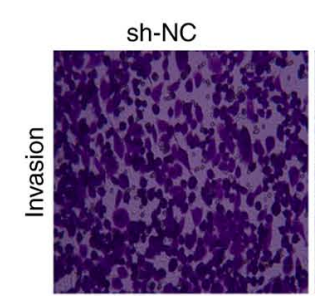

Sh-LINC00657-1

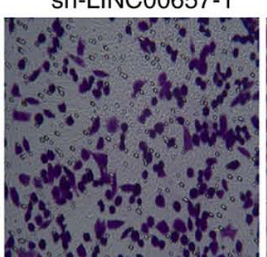

sh-LINC00657-1+ miR-520h inhibitor

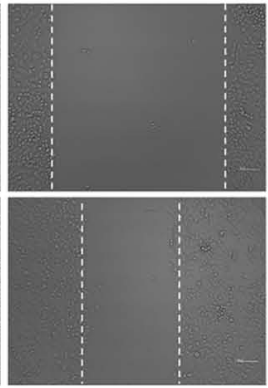

sh-LINC00657-1+ miR-520h inhibitor

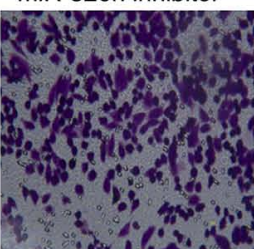

sh-LINC00657-1+ pcDNA-CKS1B

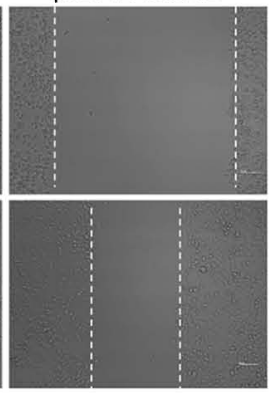

sh-LINC00657-1+ pcDNA-CKS1B

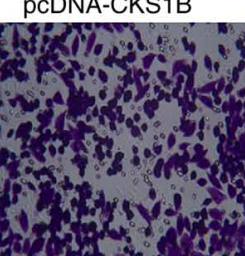

PACA-2

- sh-NC $=$ sh-LINC00657-1 o 80 sh-LINC00657-1+miR-520h inhibitor

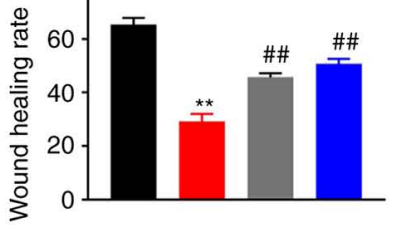

PACA-2

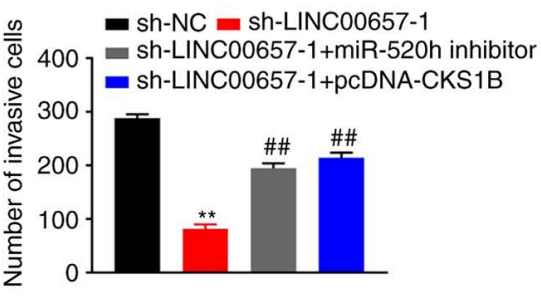

Figure 6. LINC00657 knockdown inhibits pancreatic cancer tumorigenesis by regulating miR-520h and CKS1B expression. (A) The expression of CKS1B protein was detected via western blotting in PACA-2 cells transfected with pcDNA-NC or pcDNA-CKS1B. ${ }^{* *} \mathrm{P}<0.01$ vs. pcDNA-NC. (B) Cell viability was

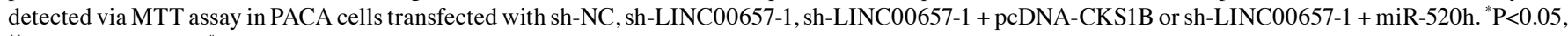
${ }^{* *} \mathrm{P}<0.01$ vs. sh-NC; ${ }^{\mathrm{P}}<0.05$ vs. sh-LINC00657-1. (C) Cell migration was examined via wound healing assay and (D) cell invasion was detected via Transwell assay in PACA-2 cells transfected with sh-NC, sh-LINC00657-1, sh-LINC00657-1 + pcDNA-CKS1B or sh-LINC00657-1 + miR-520h. Magnification, x400. ${ }^{* *} \mathrm{P}<0.01$ vs. sh-NC; ${ }^{\#} \mathrm{P}<0.01$ vs. sh-LINC00657-1. NC, negative control; CKS1B, cyclin-dependent kinases regulatory subunit 1 ; miR, microRNA; sh, short hairpin; OD, optical density.

CKS1B. Further rescue experiments revealed that miR-520h inhibition and CKS1B overexpression alleviated the inhibition of LINC00657 knockdown on the viability, migration and invasion of PACA-2 cells. As LINC00657 interacted with miR-520h and miR-520h directly targeted CKS1B, it was concluded that LINC00657 knockdown may suppress PC development by regulating the miR-520h/CKS1B axis.

In conclusion, it was revealed that LINC00657 expression was increased in PC tissues and cell lines compared with healthy tissues and control cells, respectively. Silencing LINC00657 suppressed the viability, migration and invasion of PC cells by regulating the miR-520h/CKS1B axis, indicating that LINC00657 may constitute a novel target for PC treatment. The present study may offer a potential target for PC therapy.

\section{Acknowledgements}

Not applicable.

\section{Funding}

No funding was received.

\section{Availability of data and materials}

The datasets used and/or analyzed during the current study are available from the corresponding author on reasonable request.

\section{Authors' contributions}

PL, HW and GC made substantial contributions to the conception and design of the study. HW and GC performed the experiments. PL, YT, SS, YM and YX made substantial contributions to the acquisition, analysis and interpretation of data, as well as the drafting and revision of the manuscript. All authors confirmed the authenticity of all the raw data. All authors have read and approved the final manuscript.

\section{Ethics approval and consent to participate}

All patients signed informed consents and the Ethics Committee of the Affiliated Hospital of Beihua University approved the present study (Jilin, China; approval no. 20-18). 


\section{Patient consent for publication}

Not applicable.

\section{Competing interests}

The authors declare that they have no competing interests.

\section{References}

1. Oberstein PE and Olive KP: Pancreatic cancer: Why is it so hard to treat? Therap Adv Gastroenterol 6: 321-337, 2013.

2. Ferlay J, Soerjomataram I, Dikshit R, Eser S, Mathers C, Rebelo M, Parkin DM, Forman D and Bray F: Cancer incidence and mortality worldwide: Sources, methods and major patterns in GLOBOCAN 2012. Int J Cancer 136: E359-E386, 2015.

3. Ilic M and Ilic I: Epidemiology of pancreatic cancer. World J Gastroenterol 22: 9694-9705, 2016.

4. Xu XH, Zeng XY, Wang LJ, Liu YN, Liu JM, Qi JL, Yin P and Zhou MG: The disease burden of pancreatic cancer in China in 1990 and 2017. Zhonghua Liu Xing Bing Xue Za Zhi 40: 1084-1088, 2019 (In Chinese).

5. GBD 2017 Pancreatic Cancer Collaborators: The global, regional, and national burden of pancreatic cancer and its attributable risk factors in 195 countries and territories, 1990-2017: A systematic analysis for the Global Burden of Disease Study 2017. Lancet Gastroenterol Hepatol 4: 934-947, 2019

6. Li Y, Vandenboom TG II, Wang Z, Kong D, Ali S, Philip PA and Sarkar FH: MiR-146a suppresses invasion of pancreatic cancer cells. Cancer Res 70: 1486-1495, 2010.

7. Brunner M, Wu Z, Krautz C, Pilarsky C, Grützmann R and Weber GF: Current clinical strategies of pancreatic cancer treatment and open molecular questions. Int J Mol Sci 20: 4543, 2019

8. Siegel RL, Miller KD and Jemal A: Cancer statistics, 2020. CA Cancer J Clin 70: 7-30, 2020.

9. Duguang L, Jin H, Xiaowei Q, Peng X, Xiaodong W, Zhennan L, Jianjun Q and Jie Y: The involvement of lncRNAs in the development and progression of pancreatic cancer. Cancer Biol Ther 18 927-936, 2017.

10. He Y, Hu H, Wang Y, Yuan H, Lu Z, Wu P, Liu D, Tian L, Yin J, Jiang $\mathrm{K}$ and Miao Y: ALKBH5 inhibits pancreatic cance motility by decreasing long non-coding RNA KCNK15-AS1 methylation. Cell Physiol Biochem 48: 838-846, 2018.

11. Deng SJ, Chen HY, Ye Z, Deng SC, Zhu S, Zeng Z, He C, Liu ML, Huang K, Zhong JX, et al: Hypoxia-induced LncRNA-BX111 promotes metastasis and progression of pancreatic cancer through regulating ZEB1 transcription. Oncogene 37: 5811-5828, 2018.

12. Lei Y, Wang YH, Wang XF and Bai J: LINC00657 promotes the development of colon cancer by activating PI3K/AKT pathway. Eur Rev Med Pharmacol Sci 22: 6315-6323, 2018.

13. Sun Y, Wang J, Pan S, Yang T, Sun X, Wang Y, Shi X, Zhao X, Guo J and Zhang X: LINC00657 played oncogenic roles in esophageal squamous cell carcinoma by targeting miR-615-3p and JunB. Biomed Pharmacother 108: 316-324, 2018.

14. Bi S, Wang Y, Feng H and Li Q: Long noncoding RNALINC00657 enhances the malignancy of pancreatic ductal adenocarcinoma by acting as a competing endogenous RNA on microRNA-433 to increase PAK4 expression. Cell Cycle 19: 801-816, 2020.

15. Acunzo M, Romano G, Wernicke D and Croce CM: MicroRNA and cancer-a brief overview. Adv Biol Regul 57: 1-9, 2015.

16. Wang J, Wang B, Ren H and Chen W: MiR-9-5p inhibits pancreatic cancer cell proliferation, invasion and glutamine metabolism by targeting GOT1. Biochem Biophys Res Commun 509: 241-248, 2019.

17. Tian S, Guo X, Yu C, Sun C and Jiang J: MiR-138-5p suppresses autophagy in pancreatic cancer by targeting SIRT1. Oncotarget 8 : 11071-11082, 2017

18. Yao R, Xu L, Wei B, Qian Z, Wang J, Hui H and Sun Y: MiR-142-5p regulates pancreatic cancer cell proliferation and apoptosis by regulation of RAP1A. Pathol Res Pract 215: 152416, 2019.

19. Wang F, Xue X, Wei J, An Y, Yao J, Cai H, Wu J, Dai C, Qian Z, $\mathrm{Xu} \mathrm{Z}$ and Miao Y: hsa-miR-520h downregulates ABCG2 in pancreatic cancer cells to inhibit migration, invasion, and side populations. Br J Cancer 103: 567-574, 2010.

20. Gao H, Gong N, Ma Z, Miao X, Chen J, Cao Y and Zhang G: LncRNA ZEB2-AS1 promotes pancreatic cancer cell growth and invasion through regulating the miR-204/HMGB1 axis. Int J Biol Macromol 116: 545-551, 2018.
21. Wei W, Liu Y, Lu Y, Yang B and Tang L: LncRNA XIST promotes pancreatic cancer proliferation through miR-133a/EGFR. J Cell Biochem 118: 3349-3358, 2017.

22. van Roessel S, Kasumova GG, Verheij J, Najarian RM, Maggino L, de Pastena M, Malleo G, Marchegiani G, Salvia R, $\mathrm{Ng} \mathrm{SC}$, et al: International validation of the eighth edition of the American joint committee on cancer (AJCC) TNM staging system in patients with resected pancreatic cancer. JAMA Surg 153: e183617, 2018

23. Livak KJ and Schmittgen TD: Analysis of relative gene expression data using real-time quantitative PCR and the 2(-Delta Delta C(T)) method. Methods 25: 402-408, 2001.

24. Zeng Z, Gao ZL, Zhang ZP, Jiang HB, Yang CQ, Yang J and Xia XB: Downregulation of $\mathrm{CKS} 1 \mathrm{~B}$ restrains the proliferation, migration, invasion and angiogenesis of retinoblastoma cells through the MEK/ERK signaling pathway. Int J Mol Med 44: 103-114, 2019.

25. Hwang JS, Jeong EJ, Choi J, Lee YJ, Jung E, Kim SK, Min JK, Han TS and Kim JS: MicroRNA-1258 inhibits the proliferation and migration of human colorectal cancer cells through suppressing CKS1B expression. Genes (Basel) 10: 912, 2019.

26. Zhang J, Liu X, Yu G, Liu L, Wang J, Chen X, Bian Y, Ji Y, Zhou X, Chen Y, et al: UBE2C is a potential biomarker of intestinal-type gastric cancer with chromosomal instability. Front Pharmacol 9: 847, 2018.

27. Goral V: Pancreatic cancer: Pathogenesis and diagnosis. Asian Pac J Cancer Prev 16: 5619, 2015.

28. Wang W, Lou W, Ding B, Yang B, Lu H, Kong Q and Fan W: A novel mRNA-miRNA-lncRNA competing endogenous RNA triple sub-network associated with prognosis of pancreatic cancer. Aging (Albany NY) 11: 2610-2627, 2019.

29. Zhang $\mathrm{R}$, Niu $\mathrm{Z}$, Pei $\mathrm{H}$ and Peng $\mathrm{Z}$ : Long noncoding RNA LINC00657 induced by SP1 contributes to the non-small cell lung cancer progression through targeting miR-26b-5p/COMMD8 axis. J Cell Physiol 235: 3340-3349, 2020.

30. Shaker OG, Ali MA, Ahmed TI, Zaki OM, Ali DY, Hassan EA Hemeda NF and AbdelHafez MN: Association between LINC00657 and miR-106a serum expression levels and susceptibility to colorectal cancer, adenomatous polyposis, and ulcerative colitis in Egyptian population. IUBMB Life 71: 1322-1335, 2019.

31. Liu H, Li J, Koirala P, Ding X, Chen B, Wang Y, Wang Z, Wang C, Zhang $\mathrm{X}$ and Mo YY: Long non-coding RNAs as prognostic markers in human breast cancer. Oncotarget 7: 20584-20596, 2016.

32. Zhang XM, Wang J, Liu ZL, Liu H, Cheng YF and Wang T: LINC00657/miR-26a-5p/CKS2 ceRNA network promotes the growth of esophageal cancer cells via the $\mathrm{MDM} 2 / \mathrm{p} 53 / \mathrm{Bcl} 2 / \mathrm{Bax}$ pathway. Biosci Rep 40: BSR20200525, 2020.

33. Chu L, Yu L, Liu J, Song S, Yang H, Han F, Liu F and Hu Y: Long intergenic non-coding LINC00657 regulates tumorigenesis of glioblastoma by acting as a molecular sponge of miR-190a-3p Aging (Albany NY) 11: 1456-1470, 2019.

34. Yuan X, Ma R, Yang S, Jiang L, Wang Z, Zhu Z and Li H: MiR-520g and miR-520h overcome bortezomib resistance in multiple myeloma via suppressing APE1. Cell Cycle 18: 1660-1669, 2019.

35. Su JL, Chen PB, Chen YH, Chen SC, Chang YW, Jan YH, Cheng X, Hsiao M and Hung MC: Downregulation of microRNA miR-520h by E1A contributes to anticancer activity. Cancer Res 70: 5096-5108, 2010.

36. Zhou T, Wu L, Ma N, Tang F, Zong Z and Chen S: LncRNA PART1 regulates colorectal cancer via targeting miR-150-5p/miR-520h/CTNNB1 and activating Wnt/ $\beta$-catenin pathway. Int J Biochem Cell Biol 118: 105637, 2020.

37. Stella F, Pedrazzini E, Baialardo E, Fantl DB, Schutz N and Slavutsky I: Quantitative analysis of CKS1B mRNA expression and copy number gain in patients with plasma cell disorders. Blood Cells Mol Dis 53: 110-117, 2014.

38. Shrestha S, Yang CD, Hong HC, Chou CH, Tai CS, Chiew MY, Chen WL, Weng SL, Chen CC, Chang YA, et al: Integrated MicroRNA-mRNA analysis reveals miR-204 inhibits cell proliferation in gastric cancer by targeting CKS1B, CXCL1 and GPRC5A. Int J Mol Sci 19: 87, 2017.

39. Fujita Y, Yagishita S, Hagiwara K, Yoshioka Y, Kosaka N, Takeshita F, Fujiwara T, Tsuta K, Nokihara H, Tamura T, et al: The clinical relevance of the miR-197/CKS1B/STAT3-mediated PD-L1 network in chemoresistant non-small-cell lung cancer. Mol Ther 23: 717-727, 2015.

40. Hu M, Wang M, Lu H, Wang X, Fang X, Wang J, Ma C, Chen X and $\mathrm{Xia} \mathrm{H}$ : Loss of miR-1258 contributes to carcinogenesis and progression of liver cancer through targeting CDC28 protein kinase regulatory subunit 1B. Oncotarget 7: 43419-43431, 2016. 